\title{
Physical and fitness characteristics of successful Gaelic footballers
}

\author{
AWS Watson \\ Sports Injuries Research Centre, University of Limerick, Ireland
}

\begin{abstract}
Anthropometric and fitness observations were made on 32 members of a top level Gaelic football squad that reached the All Ireland final in the year in which these measurements were taken. The subjects were found to be large and well muscled with a mean somatotype of 2.6:5.6:3.1 (endomorphy:mesomorphy:ectomorphy). Body fat content of the whole squad averaged $15.0 \%$ but the most successful group of players averaged $12.4 \%$. The body mass index (BMI) of the group was high and averaged $24.7 \mathrm{~km} \cdot \mathrm{m}^{-2}$. This group of Gaelic footballers was found to be taller and heavier than top level soccer players but smaller than Australian rules and American footballers. At $58.6 \mathrm{ml} \cdot \mathrm{min}^{-1} \cdot \mathrm{kg}^{-1}$ maximum oxygen uptake $\left(\mathrm{VO}_{2 \max }\right)$ was higher than that reported for rugby players and American footballers and is probably similar to that of professional soccer players. Scores on three lung function tests: (1) forced vital capacity (FVC), (2) forced expiratory volume during 1 s $\left(\mathrm{FEV}_{1}\right)$, and (3) peak expiratory flow rate (PEFR) were between $112 \%$ and $115 \%$ of the values predicted from height and age. There were wide variations in flexibility among the members of the group, the best individuals being as flexible as elite track and field athletes while the worst were less flexible than untrained subjects. Vertical jump scores were high and averaged $503 \mathrm{~mm}$. The fitness observations made on this group of elite Gaelic footballers showed that they were not only fitter but more homogeneously fit than rugby players and American footballers and their fitness was generally similar to that reported for professional soccer players.

(Br J Sports Med 1995; 29: 229-231)
\end{abstract}

Keywords: aerobic capacity; flexibility; somatotype; lung function; physique

Gaelic football is the most popular and widely played of the Irish team sports. The game is also played in the USA, Canada, and the UK and other places where there is a significant imigrant Irish community. It has similarities to Australian rules football, and joint competitions between the two codes have been held. Despite being a widely played field game Gaelic football has largely escaped the attention of sports scientists and few data on the physical characteristics of participants are available. A recent study of the flexibility and body mechanics of players of the companion game, hurling, is available ${ }^{1}$ but the only other published study of Gaelic footballers appears to be confined to an examination of changes in physical working capacity at a heart rate of

Address for correspondence: AWS Watson, Sports Injuries Research Centre, University of Limerick, Ireland.
170 beats per minute $\left(\mathrm{PWC}_{170}\right)^{2}$. The present paper presents some physical and fitness characteristics of top level Gaelic footballers.

\section{Methods}

The subjects were 32 members of the panel of a successful county Gaelic football team that had an excellent record in top level competition and which reached the final of the All Ireland championship in the year in which this investigation was carried out. All players had many years of experience of Gaelic football and during the current season trained or played at least three times per week. Measurements on the players were first taken in December or January and were then repeated in April before the start of the championship season. The data collected in April, following a period of pre-season training, are presented in this paper.

Height was measured using a Harpenden portable stadiometer. The subject stood on the instrument at full stretch, without shoes or socks. He stood as straight as possible against the vertical upright of the instrument with his feet together and the backs of head, shoulders, buttocks, calves and heels in contact with the upright. The subject looked straight ahead so that the top of the external auditory meatus was level with the zygoma. A horizontal measuring board was lowered firmly onto the top of the head. The subject's hair was pressed flat. The measurement was recorded to the next succeeding millimetre.

Weight was measured on a previously calibrated beam balance which was read to the nearest $0.05 \mathrm{~kg}$. The subject wore underwear, swimming trunks, or was measured in the nude. Body fat content was estimated from six skinfolds which were taken on the triceps, biceps, abdomen, front thigh, lower back, and gluteal sites using Harpenden skinfold calipers. Body fat content was then estimated according to the equation of Watson. ${ }^{3}$ This procedure has been shown to produce estimates that correlate highly with those made from body density in athletic Irish subjects.

The following aspects of flexibility were measured: spinal flexion, hip abduction, hip flexion, hip hyperextension, ankle dorsiflexion, and shoulder hyperextension. All measurements were carried out on specially constructed test rigs as described by Watson. ${ }^{3}$ The equipment was fitted with microswitches in order to detect and prevent movement in parts of the body 
that were required to remain stationary during the tests. The subjects wore running shorts or swimming trunks for the flexibility tests and were measured without a warm up, as this protocol has been found to increase the reliability of the measurement. Two attempts were allowed at each test, the best result being recorded as the subject's score.

The lung function tests FVC, FEV 1 , PEFR, and peak inspiratory flow rate (PIFR) were all measured using an electronic spirometer (Vitalograph). This instrument is based on the pneumotachograph principle. It was calibrated before the testing of each subject using the air expelled from a 1 litre syringe. Each subject was given very careful instructions on the protocol for each of the tests and was allowed up to six attempts at each. The best result was recorded as the subject's score. The scores were then converted to a percentage of the age and size corrected norms for each subject. It was found that considerable care was necessary in preparing the subjects for the lung function tests in order to obtain results that were reproducible and useful.

Aerobic capacity was measured as the maximum oxygen uptake of the subject while cycling on a Monarch bicycle ergometer. The subject warmed up before the test and then exercised at three increasing workloads from which $\mathrm{PWC}_{170}$ was computed. The workload was then increased until a plateau in maximum oxygen uptake was obtained or until successive readings did not differ by more than $2 \%$. The subject's expired air was collected in Douglas bags and gas volumes were measured with a Parkinson-Cowan gas meter. The oxygen content of the expired air was measured with a Servomex gas analyser calibrated with gases previously determined with a Lloyd-Haldane gas analyser.

Vertical jump was measured using a board fixed to a vertical wall. The subject's standing reach was subtracted from his jump-reach and the best of three attempts was recorded.

Somatotype was determined by the procedure described by Sheldon ${ }^{4}$ on a representative sample of 12 members of the squad.

The reliability of the measurement on this group of subjects was determined by carrying out duplicate determinations, separated by a period of between one and three days in a subset of 10 of the subjects. The $95 \%$ confidence limits of each determination were computed as a percentage of the mean score for each test as described by Watson. ${ }^{3}$ Descriptive statistics and a matrix of Pearson product-moment correlation coefficients for the data were computed using a 486 personal computer running a standard commercial spreadsheet.

\section{Results and discussion}

The results of the measurements taken on top level Gaelic footballers are listed in Table 1 together with the $95 \%$ confidence limits for each determination. The reliabilities of the determinations are similar to those obtained in other studies on this type of subject.

The heights and weights of the top level Gaelic footballers examined in this study were greater than those reported for top level soccer players ${ }^{5-8}$ but were
Table 1. Physical and fitness characteristics of top level Gaelic footballers

\begin{tabular}{|c|c|c|}
\hline Measurement & Mean (s.d.) & $\begin{array}{c}95 \% \\
\text { Confidence } \\
\text { limits (\%) }\end{array}$ \\
\hline Age (years) & $25.5(4.1)$ & \\
\hline Height $(\mathrm{mm})$ & $1814(82)$ & 0.22 \\
\hline Weight (kg) & $81.9(6.9)$ & 0.12 \\
\hline$\%$ fat & $15.0(4.2)$ & 7.2 \\
\hline Body mass index $\left(\mathrm{kg} \cdot \mathrm{m}^{-2}\right)$ & $24.7(1.3)$ & \\
\hline Flexibility — spinal $(\mathrm{cm})$ & $2.5(5.2)$ & 9.1 \\
\hline $\begin{array}{l}\text { Flexibility-hip abduction } \\
\text { (degrees) }\end{array}$ & $54.4(6.6)$ & 8.7 \\
\hline $\begin{array}{l}\text { Flexibility-hip flexion } \\
\text { (degrees) }\end{array}$ & $72.0(8.1)$ & 7.8 \\
\hline $\begin{array}{l}\text { Flexibility - hip hyperextension } \\
\text { (degrees) }\end{array}$ & $23.3(7.3)$ & 6.6 \\
\hline $\begin{array}{l}\text { Flexibility-ankle dorsiflexion } \\
\text { (degrees) }\end{array}$ & $33.8(4.6)$ & 7.8 \\
\hline Flexibility-shoulder (degrees) & $27.5(7.6)$ & 8.8 \\
\hline FVC (litre) & $6.0(0.5)$ & 6.7 \\
\hline $\mathrm{FEV}_{1}$ (litre) & $4.9(0.5)$ & 6.7 \\
\hline PEFR (litre $\cdot \min ^{-1}$ ) & 787 (103) & 7.8 \\
\hline PIFR (litre $\left.\cdot \min ^{-1}\right)$ & $740(230)$ & 10.2 \\
\hline FCV-size corrected $(\%)$ & $115(11)$ & \\
\hline $\mathrm{FEV}_{1}$-size corrected $(\%)$ & $112(10)$ & \\
\hline PEFR-size corrected (\%) & $114(12)$ & \\
\hline PIFR — size corrected (\%) & $101(15)$ & \\
\hline $\mathrm{PWC}_{170}(\mathrm{~W})$ & $246(32)$ & 6.6 \\
\hline $\mathrm{PWC}_{170}\left(\mathrm{~W} \cdot \mathrm{kg}^{-1}\right)$ & $3.26(0.39)$ & \\
\hline Vertical jump (mm) & $503(58)$ & 7.8 \\
\hline$\dot{\mathrm{V}} \mathrm{O}_{2 \max }\left(\right.$ litre $\left.\cdot \min ^{-1}\right)$ & $4.69(0.4)$ & 9.7 \\
\hline$\dot{\mathrm{V}} \mathrm{O}_{2 \max }\left(\mathrm{ml} \cdot \mathrm{min}^{-1} \cdot \mathrm{kg}^{-1}\right)$ & $58.6(3.8)$ & \\
\hline Endomorphy & $2.6(0.7)$ & \\
\hline Mesomorphy & $5.6(0.5)$ & \\
\hline Ectomorphy & $3.1(0.7)$ & \\
\hline
\end{tabular}

less than those for both American footballers and Australian rules footballers. ${ }^{9-11}$ Rugby players show a greater range of size, particularly in body weight, than exponents of the other codes of football. ${ }^{12}$ The typical rugby back is smaller than the present sample of subjects, while many members of the scrum are considerably heavier.

The average mesomorphy level of the present group of subjects was extremely high, while endomorphy was slightly below average for the population as a whole. The mean BMI of the subjects was also very high at $24.7 \mathrm{~kg} \cdot \mathrm{m}^{-2}$, while the mean percentage of fat was average at $15.0 \%$. Individual fat values varied between $8.4 \%$ and $18.4 \%$, with goalkeepers having the highest fat levels. The most successful players (those who were selected to represent their province, were offered contracts to play Australian rules football, or received national or other awards for their footballing performances) averaged $12.4 \%$. These results indicate that the top level Gaelic footballer tends to be large, very well muscled, and with only moderate amounts of body fat. Body fat levels for other codes of football are reported to be as follows: soccer $9-19 \%{ }^{12}$; American football $4-20 \%{ }^{9}$; and rugby $10.4-19.5 \% .^{12}$

Rugby, soccer, and Gaelic football are all extremely popular games in Ireland. While Gaelic players tend to be a little larger than soccer players and of a more uniform size than rugby players, the physique differences shown in the three types of football are only 
moderate and a number of individuals excel at two or more of the codes.

The vertical jump scores of the team as a whole are similar to those for other codes of football but are lower than those reported for the Australian rules game. ${ }^{912}$ In Gaelic football jumping ability is of greatest significance in mid-field players and in this group of individuals the mean score was $580 \mathrm{~mm}$ which is as good as that for Australian rules players. ${ }^{9}$

There were wide variations in the flexibility scores of individual members of the squad. The most flexible individuals had scores that compared favourably with a group of elite track and field athletes, measured in our laboratory, who had trained systematically for flexibility over several years. The least flexible players had very poor scores on all six flexibility tests - lower than a group of untrained subjects also seen in our laboratory.

The FVC, FEV ${ }_{1}$, and PEFR of the subjects were respectively $115 \%, 112 \%$, and $114 \%$ of the age and height corrected norms for male subjects. These results are similar to those reported for soccer players. ${ }^{12}$ In contrast, American footballers appear to have below average lung function scores. ${ }^{10}$ In the present group of subjects the correlation coefficients between the results of the lung function tests FVC, FEV ${ }_{1}$ and PEFR, and $P_{W C} C_{170}$ were $0.641,0.593$, and 0.532 respectively.

At $58.6 \mathrm{ml} \cdot \mathrm{min}^{-1} \cdot \mathrm{kg}^{-1}$ the mean aerobic capacity of these Gaelic footballers compares favourably to reported values for rugby players $(46.3-59.5 \mathrm{ml}$. $\mathrm{min}^{-1} \cdot \mathrm{kg}^{-1}$ ) and American footballers (43-54 ml $\left.\min ^{-1} \cdot \mathrm{kg}^{-1}\right){ }^{8}{ }^{10}$ There are many published reports on the maximum oxygen uptake of soccer players. ${ }^{12}$ Although some individuals appear to have high aerobic capacities it seems that the average player probably has a similar level of aerobic fitness to the present group of Gaelic footballers.
Several of the members of the present squad were selected to represent their province, were offered contracts to play Australian rules football, or received national or other awards for their footballing performances. The small number involved precludes any detailed statistical analysis but the individuals concerned tended to be taller, to have superior fitness scores, better muscle development, and lower levels of body fat. These observations concur with the results of an earlier paper which suggested that size and physical fitness were determinants of success in Gaelic football. ${ }^{1}$

\section{References}

1 Hennessy L, Watson AWS. Flexibility and posture assessment in relation to hamstring injury. Br J Sports Med 1993; 27 : 243-46.

2 Watson AWS. A study of the physical working capacity of Gaelic footballers and hurlers. Br J Sports Med 1977; 11: 133-37.

3 Watson AWS. Physical fitness and athletic performance. London: Longmans, 1983.

4 Sheldon WH, Stevens SS, Tucker WB. The varities of human physique. New York: Harper, 1940.

5 White J, Mayhew JL, Piper FC. Prediction of body composition in college football players. J Sports Med Phys Fitness 1988; 20: 317-24.

6 Reilly T. An ergonomic evaluation of stress in professional football. PhD thesis, Liverpool Polytechnic, 1975.

7 Reilly T. What research tells the coach about soccer. Washington: AAHPERD, 1979.

8 Williams G, Reid RM, Coutts R. Observations on the aerobic capacity and body composition of university rugby players and professional soccer players. Br J Sports Med 1973; 7: 390-91.

9 Douge B. Football: the common threads between the games. Reilly T et al eds. London: Spon, 1988.

10 Wilmore JH, Haskell WL. Body composition and aerobic capacity of professional football players. J Appl Physiol 1972; 33: 564-67.

11 Burke LM, Read RSD, Golland RA. Australian rules football: an anthropometric study of participants. Br J Sports Med 1985; 19 : 100-3.

12 Reilly T. Football. In: Reilly $\mathrm{T}$ et al, eds. Physiology of sports. London: Spon, 1990. 